\title{
III Congresso Internacional

\section{DIVULGAÇÃO DE MATERIAIS EDUCACIONAIS SUPORTADOS PELAS TECNOLOGIAS DA INFORMAÇÃO E COMUNICAÇÃO PARA O ENSINO DE QUÍMICA}

\author{
Apresentação: Comunicação Oral
}

\author{
Rafaela da Silva Reis ${ }^{1}$; Ivoneide Mendes da Silva²; Marcelo Brito Carneiro Leão ${ }^{3}$
}

\begin{abstract}
Resumo
Com o presente trabalho, pretende-se trazer uma abordagem para os alunos e professores, de que a experimentação "física", "presencial" não é a única forma de se contextualizar ciência e vida cotidiana. Hoje se pode ir além de um laboratório para "experimentar" a química. Existem materiais educacionais gratuitos e disponíveis na rede. Com o uso de um computador, à velocidade de um clique, podem-se obter problemas em vídeos, hipermídias, webQuests, podcasts, e outros meios de visualização online e simulações em que os estudantes possam testar hipóteses, utilizando para isso os seus conhecimentos prévios. Este trabalho tem por finalidade divulgar os materiais educacionais elaborados com as tecnologias da informação e comunicação produzidos no núcleo SEMENTE para o ensino de química. Normalmente é visto essas ações como apoio às atividades escolares, porém, neste contexto, utilizou-se dois ambientes de aprendizagem: um formal (sala de aula), auxiliando os professores e estudantes da escola Estadual de Referência em Ensino Médio Ginásio Pernambucano localizado na cidade de Recife/PE, e um ambiente não formal de aprendizagem para englobar um público diverso, que já passou (ou não) pelas escolas, no Espaço Ciência, localizado na cidade de Olinda/PE. Os materiais digitais utilizados no trabalho foram elaborados na Universidade Federal Rural de Pernambuco, no Departamento de Química, por um grupo de mestres e alunos do Núcleo SEMENTE (Sistema para Elaboração de Materiais e Estratégias de ensino suportado pelas Tecnologias). A divulgação desses materiais proporcionou aos estudantes do ambiente formal e aos usuários de um espaço não formal de aprendizagem, situações de ensino relacionadas com o que acontece em seu dia-a-dia, e, assim, tiveram a oportunidade de ter contato com um processo de ensino-aprendizagem mais contextualizado. Esse trabalho também auxiliou na melhora dos materiais produzidos pelo núcleo de pesquisa SEMENTE.
\end{abstract}

Palavras-Chave: divulgação científica, tecnologias da informação e comunicação, ensino de química.

\section{Introdução}

É notória a existência de uma grande dificuldade no ensino de ciências exatas, pois nota-se em alguns alunos uma grande aversão às disciplinas relacionadas com a área por considerarem os conteúdos complexos ou pouco inteligíveis. Esta constatação, causada por vários fatores é uma das fontes da dificuldade de ensinar as disciplinas da área e influencia o aprendizado dos alunos

\footnotetext{
${ }^{1}$ Licenciatura Plena em Química, UFRPE, campus Recife, rafaelaaa.reis@hotmail.com

2 Doutoranda em Ensino das Ciências, UFRPE, campus Recife, ivonms@hotmail.com

${ }^{3}$ Doutor, UFRPE, campus Recife, mbcleao@terra.com.br
} 
causando mais aversão (WANDERLEY et. al., [s.d.])

Para trazer novidade e novas formas de contextualização, uma das formas que vem logo à mente é a experimentação, que tende a ser uma estratégia eficiente para a criação de problemas reais que permitam a contextualização e o estímulo de questionamentos de investigação. Entretanto, esse é um campo nem sempre viável. Essas atividades experimentais tradicionais de laboratório realizadas por grupos de estudantes com orientação do professor apresentam dificuldades comuns para a sua realização, como a falta de equipamentos, custo de materiais e instrumentos, inexistência de orientação pedagógica adequada e até, em alguns casos, a forma desarticulada de ensino de alguns professores, não contribuindo, assim, para uma aprendizagem eficaz. (CABRAL apud SALESSE, 2012).

Hoje existem materiais educacionais gratuitos e disponíveis na rede. Com o uso de um computador, à velocidade de um clique, podem-se obter problemas em vídeos, hipermídias, webQuests, podcasts, e outros meios de visualização online e simulações em que os estudantes possam testar hipóteses, utilizando para isso os seus conhecimentos prévios. Segundo Leão (2011), é importante percebermos a necessidade da escola em se apropriar das Tecnologias da Informação e Comunicação (TICs), em especial a Internet, integrando-as ao processo de ensino-aprendizagem através de seus protagonistas, alunos e professores, reforçando seu compromisso na formação de cidadãos conscientes do seu papel transformador numa sociedade mais justa e igualitária.

Diante do contexto apresentado a problemática em questão é: Como divulgar materiais educacionais suportados pelas TICs, produzidos no Núcleo SEMENTE (Sistema para Elaboração de Materiais e Estratégias de ensino suportado pelas Tecnologias), de forma a contribuir com um ensino de Química mais contextualizado e com a popularização da ciência?

É nesse âmbito que incide o presente trabalho, propor uma divulgação de materiais educacionais suportados pelas TICs e elaborados pelo Núcleo de pesquisa SEMENTE (Sistema para Elaboração de Materiais e Estratégias de ensino suportado pelas Tecnologias) para o ensino de química, que tem como finalidade disponibilizar para professores e alunos, programas de simulação de aulas práticas de laboratório, vídeos, hipermídias, webQuests, FlexQuest, podcasts, entre outros, no intuito de contribuir na melhoria da aprendizagem de química, e assim colaborar de maneira mais significativa para a aprendizagem dos alunos, na disposição de aproximar a teoria e a prática, de uma forma mais interativa e, dessa maneira, despertar um maior interesse dos estudantes e professores para o uso pedagógico das TIC. Esse Núcleo de pesquisa está localizado no Departamento de Química da Universidade Federal Rural de Pernambuco (UFRPE-sede) e vem proporcionando a alunos, docentes, entre outros, elaboração de materiais didáticos e oficinas pedagógicas baseadas no uso das TIC com ênfase no ensino de Química. 
Diante do exposto, tem-se como objetivo geral divulgar e disponibilizar os materiais digitais acima citados. De maneira secundária, buscou-se também atingir alguns objetivos específicos, como: 1) diminuir a distância entre Universidade e Sociedade, propiciando ao universitário a vivência e participação na solução de problemas concretos, bem como, 2) promover o acesso para a população de uma maneira geral, no intuito de contribuir para a popularização da ciência; 3) colaborar para a contextualização no aprendizado de Química; 4) oferecer aos professores materiais alternativos para realização de aulas mais dinâmicas para alunos que não tenham acesso ao laboratório; 5) propiciar aos estudantes um estímulo ao conhecimento.

O trabalho foi desenvolvido em dois ambientes de aprendizagem: um formal (sala de aula), auxiliando os professores e estudantes da escola Estadual de Referência em Ensino Médio, Ginásio Pernambucano, localizado na cidade de Recife/PE, e um ambiente não formal de aprendizagem para englobar um público diverso, que já passou (ou não) pelas escolas, no Espaço Ciência.

\section{Fundamentação Teórica}

O papel da divulgação científica vem evoluindo ao longo do tempo, acompanhando o próprio desenvolvimento da ciência e tecnologia. Pode estar orientado para diferentes objetivos, entre eles, o educacional, ou seja, a ampliação do conhecimento e da compreensão do público leigo a respeito do processo científico e sua lógica. Neste caso, trata-se de transmitir informação científica tanto com um caráter prático, com o objetivo de esclarecer os indivíduos sobre o desvendamento e a solução de problemas relacionados a fenômenos já cientificamente estudados, quanto com um caráter cultural, visando a estimular-lhes a curiosidade científica enquanto atributo humano. Nesse caso, divulgação científica pode-se confundir com educação científica. (ALBAGLI, 1996)

A divulgação científica é essencial para o desenvolvimento da ciência, uma vez que ela é responsável pela circulação de ideias e divulga resultados de pesquisas para a população em geral. Desta forma, potencializa o debate científico e instiga novos talentos para atividades de ciências, sendo utilizada também como um instrumento para tornar disponíveis conhecimentos e tecnologias que ajudem a facilitar e contextualizar o ensino (MASSARANI et. al., 2002.).

A partir disso, buscou-se fazer uma divulgação científica de materiais educacionais suportados pelas TICs, tendo em vista que a divulgação científica é uma ferramenta para modificar a realidade de uma juventude desencantada para estudar ciências, uma área percebida como difícil, excessivamente abstrata.

As tecnologias da informação e comunicação (TICs) tem se mostrado como um instrumento que pode facilitar a compreensão dos conceitos químicos, tornando-os menos abstratos, mais 
"visualizáveis" e compreensíveis do que são considerados pelos estudantes. Elas são propostas com o intuito de melhorar o desempenho dos estudantes frente aos conteúdos escolares, tornando esses assuntos menos abstratos, não minimizando o papel fundamental dos professores no processo ensino-aprendizagem, pois, de acordo com Moura et al. (2012), o professor é figura demasiadamente importante nesse meio, pois ele irá ser o intermediador entre o aluno e a tecnologia dos softwares, desmistificando a suposição de que a informática é capaz de substituir o professor.

Segundo Leão (2011), a utilização das TICs na educação está gerando uma expectativa, talvez exagerada, de que estes ambientes garantirão uma excelência na aprendizagem. Ele acredita que a mera "transfiguração" de uma roupagem antiga para a utilização de recursos tecnológicos de ponta não trará grandes mudanças. Para o sucesso desta incorporação, a utilização das TICs na educação terá que vir acompanhada de uma profunda discussão e análise das estratégias metodológicas, que possam ajudar na construção de uma aprendizagem para o aluno.

Giordan (2008, apud SILVA, 2014) afirma que às TICs apresentam para o ensino das ciências e em particular para o Ensino de Química, grande potencial enquanto ferramenta, pois, no caso da hipermídia, por exemplo, a união entre a utilização de imagens e linguagem hipertextual é particularmente atrativo para a educação, especialmente quando se considera a disposição de fenômenos do meio natural para o meio digital.

As TICs ampliaram as diferentes formas de se ter acesso aos sistemas de informação, estimulando o desenvolvimento acelerado de conhecimento para as pessoas. Elas podem ser bastante úteis no processo ensino-aprendizagem, pois nesse contexto, viabiliza o uso da informação e do conhecimento como produto do processo, da interpretação, da compreensão informacional colaborando assim, para a construção do conhecimento (NASCIMENTO, et al., 2012).

A integração das tecnologias ao processo de ensino e aprendizagem, mediante a utilização dos meios de comunicação e interação, com abordagem didática, pode favorecer a aprendizagem e o desenvolvimento dos alunos via inserção digital (KENSKI, 2004).

Para Vaz, Vilela-Ribeiro e Soares (2012), as TIC são de suma importância, pois, permitem que a escola não seja o único nem o principal espaço em que possa ocorrer a aprendizagem, uma vez que, com as mídias digitais e os espaços virtuais isto pode ocorrer em qualquer lugar.

\section{Metodologia}

Universo da pesquisa:

Utilizou-se a divulgação desses materiais não só como apoio às atividades escolares, mas também num contexto não formal para o alcance de um público diversificado. Os materiais utilizados em cada ambiente foram diferentes, tendo em vista que, no ambiente formal, foi seguido 
a sequência dos conteúdos curriculares a serem trabalhados pelo professor com os alunos na época da aplicação da intervenção e, no ambiente não formal, levamos em conta a idade e experiências prévias dos alunos. Todos os materiais utilizados foram disponibilizados pelo núcleo SEMENTE.

Etapas da intervenção:

$1^{\circ}$. Etapa:

A primeira etapa de abordagem foi realizada em um ambiente formal de aprendizagem, em turmas do $1^{\circ}$ Ano do Colégio EREM Ginásio Pernambucano (Recife/PE), com alunos na faixa etária de 13 a 17 anos. O conteúdo que o professor estava abordando na época da intervenção era Modelos Atômicos, portanto, foram escolhidos e utilizados os recursos da hipermídia sobre Modelos Atômicos e o Vídeo com o uso do Modelo de Bohr, elaborados pelo núcleo SEMENTE.

Em apoio à atividade escolar, foi apresentado o material para a turma em questão, após a abordagem do professor de química do colégio. O professor, em aula tradicional, explicou todo o conteúdo de Modelos Atômicos para a turma. Na semana seguinte, com os recursos do computador e data show disponibilizados pela escola, foi apresentado para a turma a hipermídia de "Modelos Atômicos" disponibilizada no site do núcleo SEMENTE. Ao mostrar a hipermídia para os alunos, logo eles se interessaram pelo dinamismo que o recurso traz. Foi dito para os alunos que esse recurso está ao alcance deles e que eles podiam ter acesso em casa, pelo seu próprio computador, e, dessa forma, compreender e se aprofundar melhor no assunto ministrado pelo professor em sala. A exposição foi feita no data show disponibilizado pela escola e os alunos foram acompanhando como poderiam acessar a plataforma. Os alunos liam o que estava em cada página da hipermídia e iam acompanhando a sua mudança à cada clique.

Também foi disponibilizado para os alunos o recurso do vídeo Elétron-Gol do Modelo de Bohr, com a finalidade de associar os efeitos dos fogos de artifício aos conteúdos de química que podem ser trabalhados com os mesmos e, portanto, trazer a contextualização para a sala de aula. Esse vídeo também está ao alcance de todos, disponível na internet no site do SEMENTE.

Antes de ser exposto para a turma, foi informado aos alunos que o vídeo seria uma forma de contextualizar o modelo de Bohr. Ele também foi reproduzido no data show disponibilizado pela escola. Após o vídeo, os alunos conversaram um pouco com o professor sobre a contextualização que o vídeo trazia sobre os fogos de artifício e responderam ao questionário.

A divulgação da lista com os materiais digitais produzidos pelo Núcleo SEMENTE também foi realizada através de panfletos distribuídos com informações do site (www.semente.pro.br atualmente em reformulação). Os materiais digitais foram divulgados aproximadamente para 400 alunos de diferentes turmas da referida escola, pelo número de confecção dos panfletos. 
$2^{\circ}$. Etapa:

A segunda etapa da abordagem de intervenção foi realizada no Espaço Ciência (Olinda/PE) em um espaço não formal de aprendizagem. O grupo continha 23 pessoas e foi utilizado como recurso uma FlexQuest elaborada por pesquisadores do Núcleo SEMENTE.

A FlexQuest escolhida e utilizada tem o conteúdo referente a "Radioatividade", com o intuito de conhecer a capacidade que alguns elementos fisicamente instáveis possuem de emitir energia sob forma de partículas ou radiação eletromagnética, e, portanto, analisar criticamente seus malefícios e benefícios.

A divulgação também foi realizada através de panfletos confeccionados com informações de outros materiais como hipermídia, vídeos, podcast, entre outros. O panfleto foi o mesmo que foi utilizado na EREM Ginásio Pernambucano. Foi feita apenas uma alteração na capa.

Instrumentos de coleta de dados

Tendo em mente o objetivo do trabalho, elaborou-se um questionário com perguntas fechadas, para respostas objetivas, com o intuito de analisar se os estudantes/usuários já tinham tido acesso a algum desses tipos de materiais disponibilizados. Os questionários eram distintos para cada etapa, tendo em visto que o material utilizado em cada intervenção foi diferente.

Na primeira etapa, no Ginásio Pernambucano, o questionário foi dividido em 2 partes: Item qualidade e Item finalidade:

Quanto à qualidade do hipermídia Modelos Atômicos:

( ) Texto difícil de entender ( ) Texto fácil de entender ( ) Texto não interessante

( ) Consegui relacionar a imagem c/ o texto ( ) Não consegui relacionar a imagem c/ o texto Quanto à qualidade do vídeo Elétron-Gol:

( ) Ótima para imagem （ ) Média para imagem （ ) Baixa para imagem

( ) Ótima para áudio ( ) Média para áudio ( ) Baixa para áudio

Quanto à finalidade do hipermídia Modelos Atômicos:

( ) Entendi, achei interessante e gostei ( ) Entendi, mas não gostei ( ) Não entendi e não gostei

( ) Nunca tinha visto hipermídias de Química ( ) Já vi hipermídias de Química

Quanto à finalidade do vídeo Elétron-Gol:

( ) Entendi, achei interessante e gostei ( ) Entendi, mas não gostei ( ) Não entendi e não gostei

( ) Nunca tinha visto vídeos englobando Química ( ) Já vi vídeos englobando Química

O item qualidade foi utilizado para melhoramento dos materiais no núcleo SEMENTE. Já o item finalidade serviu como dado para verificar se os alunos já tinham tido acesso a materiais como esses. 
Na segunda etapa, o questionário foi realizado para que os usuários do Espaço Ciência, que tiveram acesso à intervenção, respondessem marcando um "X" em uma ou mais características.

Em relação ao uso da FlexQuest de Radioatividade, atribua uma ou mais características:

( ) nunca tinha escutado falar sobre "radioatividade"

( ) já tinha escutado falar sobre "radioatividade"

( ) os textos da FlexQuest eram difíceis de entender

( ) os textos da FlexQuest eram fáceis de entender

( ) nunca tinha visto programas de computador ou uso de recursos assim nas aulas de Química

( ) antes dessa atividade eu já tinha usado vídeos e outros recursos para aprender Química

( ) é um recurso estimulador de aprendizagem

( ) não gerou estímulo para aprender

( ) este recurso me deu uma melhor compreensão do uso de radioatividade

( ) com este recurso eu continuei sem entender sobre o assunto "radioatividade"

( ) entendi os malefícios e benefícios da radioatividade

( ) não vejo perigo em estar exposto a um material radioativo e não sei os benefícios

\section{Resultados e Discussão}

$\mathrm{Na}$ primeira etapa foram aplicados questionários nas turmas de $1^{\circ}$ ano para avaliação dos materiais quanto a sua finalidade e qualidade. O item "qualidade" foi utilizado para aprimorar os materiais educacionais do Núcleo SEMENTE. E o item "finalidade" foi usado como parâmetro para avaliar a aceitabilidade do material por parte dos alunos e para avaliar seu uso em sala de aula. Abaixo segue um recorte dos dados de uma amostra com 38 alunos de uma das turmas. (Gráficos 1 e 2).

Gráfico 1. Quanto à finalidade do Vídeo Modelo de Bohr. Fonte: Própria

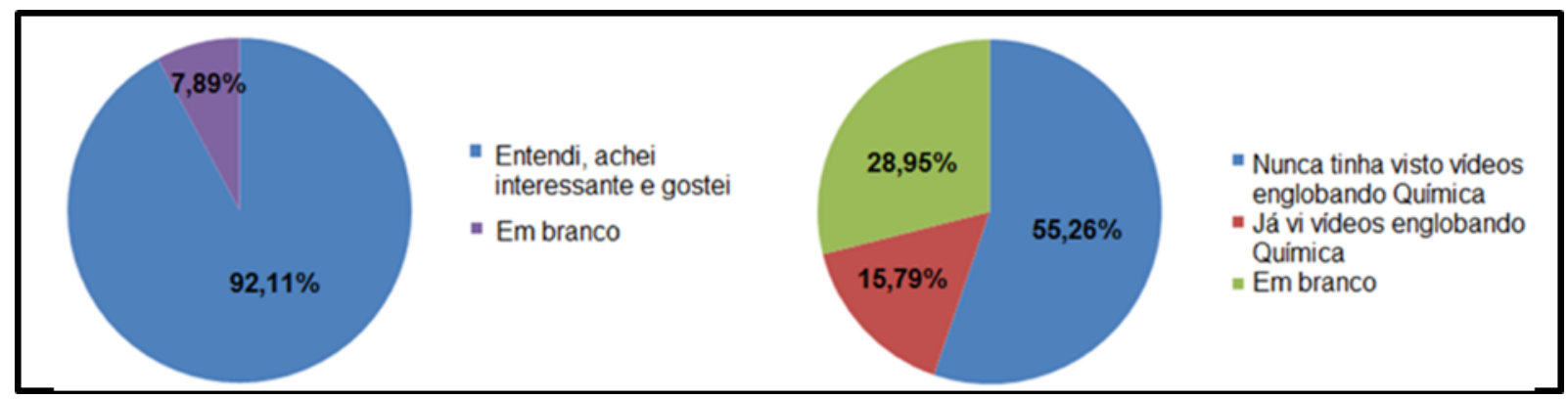


Gráfico 2. Quanto à finalidade da Hipermídia de Modelos Atômicos. Fonte: Própria

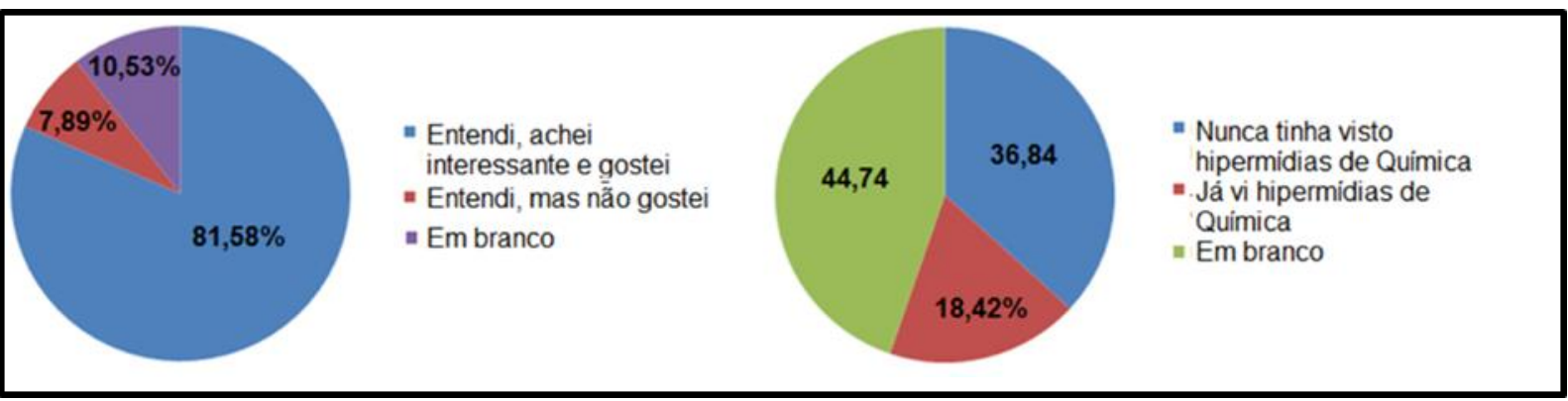

Na segunda etapa a FlexQuest sobre Radioatividade permitiu analisar o mesmo conteúdo inserido em diversos contextos, favorecendo a contextualização e uma melhor compreensão sobre a temática abordada. Para tal, no final da intervenção foi aplicado como instrumento um questionário, no intuito de descrever a importância do uso desse tipo de material em um ambiente não formal de aprendizagem. O questionário foi elaborado de forma que as questões fossem respondidas de forma objetiva. (Quadro 1)

Quadro 3. Respostas dos questionários no Espaço Ciência. Fonte: Própria
Nunca ouviram sobre Radioatividade
Texto da FlexQuest fácil de entender
Nunca utilizaram computador como recurso tecnológico para aprendizagem -- 87\%
Apontaram o recurso utilizado como recurso estimulador de aprendizagem - 95,7\%
Usuários apontaram agora compreensão do uso da radioatividade $91,3 \%$
Usuários disseram estar cientes perigos e benefícios da radioatividade $95,7 \%$

$60,9 \%$ $91,3 \%$

Na Fig.1 pode-se observar que $28,95 \%$ dos alunos deixaram a informação em branco e $55,26 \%$ disseram nunca ter visto vídeos englobando química. Tendo em vista a popularidade de vídeos na internet, fica-se a pergunta: será que esses alunos nunca viram tais vídeos ou não os relacionaram ao aprendizado de química?

Na Fig.2 nota-se um percentual de 44,74\% para respostas em branco quanto à visualização de hipermídias. Pode-se dizer que o conceito do que é a hipermídia talvez tenha gerado dúvida nos alunos sobre já terem tido acesso ou não a esse tipo de material.

Como pode ser visto pela análise de dados, os materiais divulgados foram de extrema importância para os estudantes/usuários, tendo em vista que muitos nunca tinham tido acesso a esses tipos de materiais. Os dados descritos neste item serviram apenas para situar a graduanda quanto à importância da divulgação dessas tecnologias para o ensino de química.

Na primeira etapa, a estudante conseguiu oferecer aos professores materiais alternativos para realização de aulas contextualizadas e dinâmicas para alunos que não tenham acesso ao laboratório; 
disponibilizar para os professores da rede pública materiais digitais que utilizem a temática do conhecimento dos estudantes; propiciar aos estudantes um estímulo ao conhecimento, tendo em vista que eles relataram no quadro 1 que o recurso era estimulador.

$\mathrm{Na}$ segunda etapa, a estudante conseguiu diminuir um pouco a distância entre a Universidade e a Sociedade, tendo em vista que muitos frequentadores do Espaço Ciência não frequentavam a escola e não tinham acesso a esse tipo de material educativo com uso das TICs. Cabe ressaltar que a FlexQuest "Radioatividade" deu oportunidade para que o usuário identificasse diferentes aplicações relacionados à radioatividade e a inter-relação entre essas aplicações, permitindo com isso, a construção de um conhecimento flexível a partir de informações advindas da internet e da televisão. Também satisfez na ideia de ser um recurso estimulador de aprendizagem.

\section{Conclusões}

Com as mudanças ocorridas ao longo dos séculos a forma de comunicação e divulgação da informação evoluiu. As tecnologias de informação e comunicação surgem a partir desta evolução dinamizando a forma como a informação é disseminada. As ferramentas tecnológicas proporcionam uma grande facilidade na geração, disseminação, uso e recuperações das informações.

A divulgação de materiais educacionais elaborados com uso das Tecnologias da Informação e Comunicação (TIC), produzidas pelo núcleo de pesquisa SEMENTE, proporcionou aos estudantes do ambiente formal e aos usuários de um espaço não formal de aprendizagem, situações de ensino relacionadas com o que acontece em seu dia-a-dia, e, assim, tiveram a oportunidade de ter contato com um processo de ensino e aprendizagem contextualizado.

Concluiu-se o exposto de divulgar e disponibilizar esses materiais digitais; diminuir a distância entre Universidade e Sociedade, propiciando ao universitário a vivência e participação na solução de problemas concretos; colaborar para a melhoria da qualidade do aprendizado de Química; oferecer aos professores materiais alternativos para realização de aulas mais dinâmicas para alunos que não tenham acesso ao laboratório; disponibilizar para os professores da rede pública materiais digitais que utilizem a temática do conhecimento dos estudantes; propiciar aos estudantes um estímulo ao conhecimento.

Esse trabalho também estimulou a graduanda, futura professora, na construção e montagem de seus próprios materiais e ajudou os estudantes e professores da área na busca de materiais alternativos para a realização de aulas mais dinâmicas com o uso das TIC, tendo em vista que a maior parte dos usuários do projeto nunca tinham tido acesso a esse tipo de material. Com isso, o projeto em questão auxiliou na divulgação e popularização da ciência e para um futuro melhoramento dos materiais produzidos pelo Núcleo SEMENTE. 


\section{Referências}

ALBAGLI, S. Divulgação científica: informação científica para a cidadania?. Ciência da Informação. Brasília, v. 25, n. 3, p. 396-404, set./dez. 1996. Disponível em: <http://revista.ibict.br/cienciadainformacao/index.php/ciinf/article/viewFile/465/424>. Acesso em: 22 de março de 2016.

CABRAL, J. R. R. Atividades experimentais/demonstrações e principais referenciais teóricos. Departamento de Ciências Naturais - UFSJ. São João del Rei, 2012.

GIORDAN, M. Computadores e linguagens nas aulas de ciências. Ijuí: Ed. Unijuí, 2008.

KENSKI, V. M.. Tecnologias e ensino presencial e a distância. Campinas, SP. Papirus, 2004.

LEÃO, M. B. C. Tecnologias na educação: uma abordagem crítica para uma atuação prática. Universidade Federal Rural de Pernambuco: EDU, 2011. 179 p.

MASSARANI, L., Moreira, I. e Brito, F. Ciência e Público: caminhos da divulgação científica no Brasil. Rio de Janeiro: Casa da Ciência; Centro Cultural de Ciência e Tecnologia da UFRJ, 2002.

MOURA, P. H. B.; SERRÃO, C. R. G.; FERREIRA, R. L. S.; MOYSÉS, D. A.; SILVA, M. D. B. Aplicação de Softwares Educacionais em Química: Um Estudo de caso em uma Turma do Ensino Médio em uma Escola Estadual da cidade de Belém-PA. In: Encontro Nacional de Ensino de Química e Encontro de Educação Química da Bahia, 16 e 10., Salvador. Anais eletrônicos... Salvador: UFBA, 2012. Disponível em: <http://www.portalseer.ufba.br/index.php/anaiseneq2012/article/viewFile/7998/5883> Acesso em: 19 de abril de 2016.

NASCIMENTO, B. L. Et al.; Uso das novas tecnologias no processo de ensino-aprendizagem e na divulgação $\quad$ científica. $2012 . \quad$ Disponível em: <http://portaldeperiodicos.eci.ufmg.br/index.php/moci/article/viewFile/2128/1324>. Acesso em: 23 de março de 2016.

SALESSE, A. M. T., A EXPERIMENTAÇÃO NO ENSINO DE QUÍMICA: importância das aulas práticas no processo de ensino aprendizagem, Medianeira, 2012. Disponível em: < http://repositorio.roca.utfpr.edu.br/jspui/bitstream/1/4724/1/MD_ED

UMTE_II_2012_21.pdf>. Acesso em: 27 de abril de 2016.

SILVA, I.M. A utilização das tecnologias da informação e comunicação em cursos de licenciatura em química. (Dissertação de mestrado apresentado à Universidade Federal Rural de Pernambuco). Pernambuco, 2014.

VAZ, W.F.; VILELA-RIBEIRO, E. B.; SOARES, H. F. B. S. A rede social Orkut e suas possibilidades de interação e ensino e aprendizagem de química: a visão dos moderadores das comunidades. In: Encontro Nacional de Ensino de Química e Encontro de Educação Química da Bahia, 16 e 10, Salvador. Anais eletrônicos... Salvador: UFBA, 2012. Disponível em: 
<http://www.portalseer.ufba.br/index.php/anaiseneq2012/article/view/7999>. Acesso em: 19 de abril de 2016.

WANDERLEY, K. A. et. al. Pra gostar de química: um estudo das motivações e interesses dos alunos da 8 a série do ensino fundamental sobre química. Resultados preliminares. In: CNNQ, 1, [s.d.]. Universidade Federal de Pernambuco. Resumos. Pernambuco: Universidade Federal de Pernambuco, [s.d.]. p.2. 